\title{
Os Efeitos Advindos da Condenação do Brasil no Caso Damião Ximenes Lopes na Corte Interamericana de Direitos Humanos por Violação aos Direitos Previstos no Pacto de San José da Costa Rica
}

\begin{abstract}
Bruna Pereira Aquino
Advogada. Mestre em Direitos e Garantias Fundamentais pela Faculdade de Direito de Vitória. Especialista em Direito e Processo Tributário pela Faculdade de Direito de Vitória. Egressa da Faculdade de Direito de Vitória. brunapereiraaquino@gmail.com

Gilsilene Passon Francischetto

Possui Graduação em Direito pela Universidade Federal do Espírito Santo (1998) e em Pedagogia pela Universidade Norte do Paraná - Unopar (2013); Mestrado em Direito pela Universidade Federal de Santa Catarina (2001), Doutorado em Direito pela Universidade Gama Filho (2005), Pós-Graduação em Docência do Ensino Superior pela Universidade Norte do Paraná - Unopar - e Pós-Doutorado em Ciências Sociais pelo Centro de Estudos Sociais da Universidade de Coimbra (2008), sob a orientação do professor doutor Boaventura de Sousa Santos. Atualmente é professora titular na Graduação, Pós-Graduação, Mestrado e Doutorado da Faculdade de Direito de Vitória - FDV. gilsilenepasson@uol.com.br
\end{abstract}

O presente artigo analisa quais as consequências advindas da sentença condenatória internacional, proferida em desfavor do Brasil pela Corte Interamericana de Direitos Humanos no caso Damião Ximenes Lopes, tais como condenação pecuniária, elaboração de estrutura de apoio para pessoas com adoecimento mental e capacitação dos profissionais da área da saúde mental. O primeiro tópico traz uma análise dos direitos humanos no pós-Segunda Guerra Mundial e trata do Sistema Interamericano de Direitos Humanos, dando ênfase ao Pacto de San José da Costa Rica (1969). O segundo item versa sobre a posição adotada pelo Brasil como signatário da Corte Interamericana de Direitos Humanos. O terceiro tópico trata das particularidades do caso Damião Ximenes Lopes versus Brasil na Corte Interamericana de Direitos Humanos. Finalmente, o quarto e último item discorre sobre as consequências advindas da condenação do Estado brasileiro no caso Damião Ximenes Lopes. Assim, o presente artigo objetiva descrever o papel da Corte Interamericana de Direitos Humanos na proteção dos direitos humanos, bem como apontar seu funcionamento, especificar as características do caso Damião Ximenes Lopes, descrevendo e analisando quais as consequências advindas da condenação do Brasil, nesse caso, no que diz respeito ao enfrentamento das questões relativas aos doentes mentais. Assim, por meio do método dialético e de revisão bibliográfica, o artigo busca responder ao seguinte questionamento: Quais os efeitos advindos da condenação do Brasil na Corte Interamericana de Direitos Humanos por violação a vários direitos do Pacto de San José da Costa Rica no caso Damião Ximenes Lopes? Palavras-chave: Corte Interamericana de Direitos Humanos. Adoecimento mental. Invisibilidade. Damião Ximenes Lopes. Direitos humanos.

\section{THE EFFECTS OF BRAZIL'S CONVICTION IN DAMIÃO XIMENES LOPES CASE IN INTER-AMERICAN COURT} OF HUMAN RIGHTS FOR VIOLATION OF THE RIGHTS OF SAN JOSE CONVENTION

ABSTRACT

This article analyzes the consequences of the international conviction of Brazil by the Inter-American Court of Human Rights in Damião Ximenes Lopes case, such as pecuniary conviction, the elaboration of a support structure for people with mental illness and the training of professionals of mental health area. The first chapter analyzes Human Rights after World War II and talk about the inter-American system of Human Rights, emphasizing the Pact of San José of Costa Rica (1969). The second chapter analyzes the position adopted by Brazil as a member of the Inter-American Court of Human Rights. The third chapter analyzes with the particularities of the case Damião Ximenes Lopes v. Brazil in the Inter-American Court of Human Rights. Finally, the last chapter analyzes the consequences from the condemnation of the Brazilian State in Damião Ximenes Lopes case. The purpose of this article is to describe the role of the Inter-American Court of Human Rights for protection of human rights, as well as to indicate its functioning, to specify the characteristics of the Damião Ximenes Lopes case, describing and analyzing the consequences of Brazil's condemnation in this case with regard to addressing mental health issues. Thus, through the dialectical method and a bibliographic review, the article seeks to answer the following question: What are the effects of Brazil's conviction in the Inter-American Court of Human Rights for violation of rights of San José Pact in Damião Ximenes Lopes case?

Keywords: Inter-American Court of Human Rights. Mental illness. Invisibility. Damião Ximenes Lopes. Human rights.

1 Introdução. 2 O Sistema Interamericano de Direitos Humanos. 3 A Posição do Brasil Como Signatário da Corte Interamericana de Direitos Humanos. 40 Caso Damião Ximenes Lopes. 5 As Consequências Advindas da Condenação do Brasil na Corte Interamericana de Direitos Humanos no Caso Damião Ximenes Lopes. 6 Considerações Finais. 7 Referências. 


\section{Introdução}

Com o fim da Segunda Guerra Mundial houve uma mudança no tratamento atribuído aos direitos humanos. Isto porque, neste contexto do pós-guerra, após as incontáveis atrocidades praticadas por seres humanos contra seus pares ganharem repercussão em todo o mundo, a comunidade internacional, de uma maneira geral, entendeu ser imprescindível que os direitos humanos fossem concebidos como direitos inerentes a todas as pessoas.

Dessa maneira, para garantir proteção aos direitos inerentes aos seres humanos, bem como o amparo à dignidade humana, foram criados meios internacionalmente capazes de inibir quaisquer tipos de violações direcionadas aos direitos humanos. Para tanto, em uma perspectiva global, a Organização das Nações Unidas elaborou, em 1945, disposições sobre os direitos humanos por meio da Carta das Nações Unidas e, finalmente, em 1948, instituiu a Declaração Universal dos Direitos Humanos.

Por sua vez, em uma perspectiva regional, surgiram diversos sistemas de proteção aos direitos humanos, contudo no presente artigo a análise se restringirá à Convenção Americana de Direitos Humanos de 1969, mais conhecida como Pacto de José da Costa Rica, instituída por meio da edição da Declaração Americana de Direitos e Deveres do Homem, datada de 1948.

Juntamente com a Convenção Americana de Direitos Humanos foi criada a Corte Interamericana de Direitos Humanos, que iniciou suas atividades em 1978. Quanto à competência, de acordo com o artigo 62 da Convenção Interamericana de Direitos Humanos, a Corte poderá julgar qualquer caso relativo à interpretação e aplicação das disposições desta Convenção, entretanto deve se limitar aos fatos ocorridos a partir da ratificação de sua competência pelo Estado-parte, conforme determina o parágrafo 10 do artigo 62 (COSTA RICA, 1969).

Vale destacar que o Brasil aderiu à Convenção Interamericana de Direitos Humanos em 1992 mas apenas em 1998 foi reconhecida a competência da Corte. Ocorre que, no Estado brasileiro, a Convenção Interamericana de Direitos Humanos de 1969, ao ser incorporada pelo ordenamento jurídico, equiparava-se a uma lei ordinária, quanto à sua eficácia e hierarquia, conforme entendimento até então adotado pelo Supremo Tribunal Federal (STF) no julgamento do HC no 72.131-RJ julgado em 22 de novembro de 1995.

Somente no ano de 2004 houve uma mudança de perspectiva com a aprovação da Emenda Constitucional n ㄴ 45, observando-se que, a partir de então, o artigo 5ㅇ, § 3으, passou a estabelecer que "os tratados e convenções internacionais sobre direitos humanos que forem aprovados, em cada Casa do Congresso Nacional, em dois turnos, por três quintos dos votos dos respectivos membros, serão equivalentes às emendas constitucionais" (BRASIL, 1988).

O fato é que continuou a vigorar, até este momento, o entendimento do Supremo de que as convenções e tratados internacionais, quando recepcionados, equiparavam-se às leis ordinárias. Isto porque somente em 2008 o Supremo Tribunal Federal (STF), durante o julgamento do RE no 466.343 SP, reviu seu posicionamento e passou a reconhecer que os tratados de cunho internacional possuem força supralegal, isto é, estão acima das demais leis brasileiras, mas abaixo das normas provenientes da Constituição Federal de 1988. 
Dessa maneira, a partir desta nova percepção, eventuais condenações experimentadas pelo Brasil na Corte Interamericana de Direitos Humanos ostentariam um novo sentido. Entre os diversos casos em que o Brasil figurou como parte diante da Corte Interamericana de Direitos Humanos merece destaque o caso Damião Ximenes Lopes, pessoa com adoecimento mental que, com apenas 3 (três) dias de internação na Casa de Repouso de Guararapes (CE), veio a óbito, destacando-se que o hospital psiquiátrico apresentou laudo apontando a causa da morte como indeterminada.

A família de Damião Ximenes Lopes, indignada com o descaso do poder Judiciário e em razão da inércia e morosidade da Justiça, resolveu submeter o caso para análise da Comissão Interamericana de Direitos Humanos que, por sua vez, apresentou a demanda à Corte Interamericana, originando a denúncia no 12.237 em desfavor do Brasil.

A Corte Interamericana de Direitos Humanos recebeu a denúncia e, em 2006, condenou o Brasil, pela primeira vez, em uma sentença de mérito, em decorrência das diversas violações aos direitos humanos de pessoa com doença mental evidenciadas no caso em tela. É válido lembrar que, à época da condenação do Brasil, mais especificamente no ano de 2006, os tratados e convenções internacionais eram recepcionados com força de lei ordinária, em virtude do entendimento até então adotado pelo Supremo Tribunal Federal (STF).

Diante do exposto, por meio da utilização do método dialético, o presente artigo tem como objetivo reconhecer as consequências advindas da condenação do Brasil pela Corte Interamericana de Direitos Humanos no caso Damião Ximenes Lopes, tais como a criação de leis, a elaboração de estrutura de apoio para pessoas com deficiência mental, a capacitação dos profissionais da área da saúde mental, bem como a condenação pecuniária do Brasil.

O primeiro tópico traz uma análise dos direitos humanos no período pós-Segunda Guerra Mundial e trata do Sistema Interamericano de Direitos Humanos, dando ênfase ao Pacto de San José da Costa Rica (1969). O segundo item versa sobre a posição adotada pelo Brasil na condição de signatário da Corte Interamericana de Direitos Humanos. O terceiro tópico expõe as particularidades do caso Damião Ximenes Lopes versus Brasil na Corte Interamericana de Direitos Humanos. Por fim, o quarto e último item versa sobre as consequências advindas da condenação do Estado brasileiro no caso Damião Ximenes Lopes versus Brasil.

Nesse contexto, o artigo busca responder ao seguinte questionamento: Quais os efeitos advindos da condenação do Brasil na Corte Interamericana de Direitos Humanos por violação a vários direitos do Pacto de San José da Costa Rica no caso Damião Ximenes Lopes?

\section{Sistema Interamericano de Direitos Humanos}

Os direitos humanos, como verdadeiras reivindicações morais, "são fruto de um espaço simbólico de luta e ação social, na busca por dignidade humana, o que compõe um construído axiológico emancipatório", segundo Flávia Piovesan (2007, p. 109). Desta forma, de acordo com os ensinamentos da autora, é possível afirmar que se trata de uma categoria de direitos inerentes a todo e qualquer indivíduo em decorrência de sua condição humana.

Para Alberto Silva Santos (2012, p. 91), os direitos fundamentais ganharam relevância internacional somente após a Segunda Guerra Mundial, deixando de pertencer a um determinado Estado, isto porque passaram a ser compreendidos como direitos inerentes a toda a hu- 
manidade. Como consequência disso, os direitos humanos passaram a ser concebidos como direitos universais, indivisíveis e de cunho cosmopolita. Assim, o autor destaca que se adotou a ideia de que tais direitos não decorrem da nacionalidade do indivíduo, posto que os direitos humanos são essenciais à natureza de toda pessoa (2012, p. 102).

Neste sentido, Luciana Genro (2012, p. 19) destaca que a afirmação dos direitos humanos como preocupação universal somente se concretizou após o fim do nazismo, com esse processo sendo estimulado pelos crimes hediondos cometidos durante a Segunda Guerra Mundial. Assim, é possível afirmar que as atrocidades ocorridas durante esse período histórico contribuíram diretamente para uma mudança de perspectiva no que diz respeito aos direitos humanos.

É válido destacar que, durante anos a fio, propagou-se a ideia de que o relacionamento entre um determinado país e seus nacionais restringir-se-ia unicamente a um problema de jurisdição interna, sendo vedada a possibilidade de intervenção externa por parte de outros países ou órgãos internacionais quando da constatação de violação de direitos humanos. Ocorre que, com o passar dos anos, segundo Flávia Piovesan (2007, p. 116-117), houve um enfraquecimento da ideia de que o relacionamento entre um Estado e seus nacionais consistiria em um problema de jurisdição doméstica em decorrência da soberania estatal. Em consequência disso, progressivamente, ganhou força o entendimento de que os indivíduos, além de objetos, são também sujeitos do Direito Internacional.

Assim, sob essa nova ótica, Flávia Piovesan (2007, p. 116-117) entende que "começa a se consolidar a capacidade processual internacional dos indivíduos, bem como a concepção de que os direitos humanos não mais se limitam à jurisdição doméstica, mas constituem matéria de legítimo interesse internacional". Essa nova percepção foi importante, neste primeiro momento, para garantir a propagação dos direitos humanos, visto que, a partir de então, passou-se a vislumbrar a possibilidade de intervenção estrangeira nos Estados em que fosse constatada violação a esta categoria de direitos.

Conforme exposto anteriormente, os direitos humanos, na condição de Direito Internacional, somente se consolidaram no contexto do pós-Segunda Guerra Mundial. Alberto Silva Santos (2012, p. 91) destaca que, nesse momento, além dos enunciados elaborados para garantir a proteção dos referidos direitos, foi necessária a criação de meios eficazes para inibir eventuais violações, bem como garantir sua aplicação concreta.

Assim, em 1945 foi instituída, em âmbito global, a Organização das Nações Unidas (ONU), por meio da Carta das Nações Unidas, que trouxe algumas disposições referentes aos direitos humanos e também instituiu a Declaração Universal dos Direitos Humanos em 1948. Por sua vez, também foram instituídos, em níveis regionais, diversos sistemas de proteção dos direitos humanos que, de acordo com o autor, foram "inspirados pela noção internacional da necessidade de sua proteção em âmbito superestatal” (2012, p. 92).

Interessante destacar a crítica tecida pelo autor Boaventura de Sousa Santos, o qual pretendeu demonstrar que, na verdade, não existe universalidade no que diz respeito à difusão dos direitos humanos, tendo em vista que houve propagação desses direitos apenas sob a ótica defendida pela cultura ocidental. Em síntese, o autor entende que a história dos direitos 
humanos no período subsequente à Segunda Guerra Mundial revela que as políticas de direitos humanos estiveram, de maneira geral, a serviço dos interesses econômicos e geopolíticos dos Estados capitalistas hegemônicos (1997, p. 20).

Boaventura de Sousa Santos (1997, p. 20) entende que a marca ocidental, também compreendida como ocidental-liberal, do discurso dos direitos humanos pode ser identificada, a título exemplificativo, na Declaração Universal dos Direitos do Homem de 1948, visto que o documento, ao ser elaborado, dispensou a participação dos povos subjugados pelo colonialismo europeu, ou seja, não deu vez para a participação da maior parte dos povos do mundo. Além disso, segundo o autor, estabeleceu-se como prioridade os direitos cívicos e políticos sobre os direitos sociais, culturais e econômicos.

Gradualmente, foram-se desenvolvendo discursos e práticas contra-hegemônicos de direitos humanos, foram sendo propostas concepções não ocidentais dos direitos humanos, foram-se organizando diálogos interculturais de direitos humanos. Neste domínio, a tarefa central da política emancipatória do nosso tempo consiste em transformar conceptualização e prática dos direitos humanos de um localismo globalizado num projecto cosmopolita (SANTOS, 1997, p. 21).

Dessa forma, a fim de combater esse falso universalismo, posto que diversas culturas são excluídas da construção do significado de direitos humanos, Boaventura de Sousa Santos (1997, p. 22) propõe um diálogo intercultural sobre a concepção de dignidade humana, o que eventualmente pode desaguar em um significado "mestiço" de direitos humanos, constituindo, assim, redes de referências normativas capacitantes. Para que isso aconteça, entretanto, segundo o autor, é preciso que exista o reconhecimento de incompletudes mútuas como verdadeira condição sine qua non para a promoção de um diálogo intercultural.

Nesse sentido, Alberto Silva Santos $(2012$, p. 148) destaca que, apesar da crítica feita à ocidentalização dos direitos humanos, mesmo os autores adeptos da teoria crítica reconhecem a importância do papel desempenhado pelo Sistema Interamericano, razão pela qual não se pode desprezar as conquistas já obtidas pelos processos de lutas que culminaram com a criação do Sistema.

Apesar do dever de reconhecer os méritos do Sistema Interamericano dos Direitos Humanos, há também que constantemente fazer uma leitura crítica do mesmo, a qual poderá ampliar suas potencialidades para que cada vez mais o sistema tenha condições de cumprir com a missão de dar conta da enunciação, tutela, garantia e efetivação dos Direitos Humanos no âmbito do continente Americano (SANTOS, 2012, p. 155).

Muito embora o presente artigo detenha-se em analisar questões ligadas ao Sistema Americano de Direitos Humanos, é necessário destacar que existem muitos outros sistemas de proteção, sendo possível citar, a título exemplificativo, o Sistema Africano e o Sistema Europeu. Conforme demonstrado anteriormente, porém, ganhou força e, consequentemente, hegemonia, os sistemas difundidos por meio dos países ocidentais localizados no Hemisfério Norte.

No continente americano merece destaque a Declaração Americana de Direitos e Deveres do Homem, datada de 1948, que serviu como base fundamental para a elaboração da Convenção Americana de 1969, também chamada de Pacto de San José da Costa Rica. A re- 
ferida Convenção, integrante do Sistema Americano de Proteção dos Direitos Humanos, também foi responsável pela criação de uma Corte com competência necessária para promover a apreciação e julgamento dos casos envolvendo direitos humanos.

Embora tenha sido criada em 1969, a Corte Interamericana de Direitos Humanos entrou em vigor somente em 1978, ou seja, cerca de 10 (dez) anos após a sua criação. Com sede na cidade de San José da Costa Rica, na Costa Rica, a Corte é composta por 7 (sete) juízes com mandato de 6 (seis) anos, sendo possível apenas uma prorrogação.

Para garantir a composição da Corte, cada Estado-parte da Convenção Americana de 1969 pode indicar até 3 (três) nomes que, por sua vez, deverão ser aprovados por voto secreto da maioria absoluta dos Estados-parte, destacando-se que pelo menos um dos nomes indicados deverá ser de pessoa natural de Estado diferente do proponente.

De acordo com Flávia Piovesan (2007, p. 237), a Convenção Americana limita-se a determinar que os Estados-parte alcancem, progressivamente, a plena realização dos direitos sociais, culturais e econômicos elencados na norma internacional mediante a adoção de medidas, inclusive legislativas, que se mostrem adequadas ao que está disposto no artigo 26 da Convenção, conferindo efetividade aos direitos e liberdades enunciados. Dessa maneira, segundo a autora, não restam dúvidas de que "cabe ao Estado-parte a obrigação de respeitar e assegurar o livre e pleno exercício desses direitos e liberdades, sem qualquer discriminação" (2007, p. 237).

A Corte Interamericana de Direitos Humanos possui competência dúplice, ou seja, pode ser compreendida como órgão consultivo ou contencioso, ressaltando-se que a competência litigiosa para o julgamento dos casos é limitada aos Estados signatários da Convenção Americana de 1969 que tenham expressamente reconhecido tal jurisdição, conforme destaca Flávia Piovesan (p. 250).

Flávia Piovesan (p. 251) ensina que as decisões proferidas pela Corte Interamericana têm força jurídica vinculante sendo, portanto, obrigatórias, cabendo ao Estado-parte seu cumprimento imediato. Ocorre que, para tanto, "é necessário que o Estado reconheça a jurisdição da Corte, já que tal jurisdição é apresentada sob a forma de cláusula facultativa (p. 252).

Vale destacar que o Brasil aderiu à Convenção Americana de Direitos Humanos de 1969 somente em 1992 mas, conforme será demonstrado no tópico seguinte, não houve adesão imediata aos termos da Convenção, sob o argumento de que o Estado brasileiro "precisaria analisar a viabilidade de conformar a Convenção com o direito interno", isto porque, à época estava vigorando o regime autoritário da ditadura militar (SANTOS, 2012, p. 105). Dessa maneira, a adesão tardia do Brasil à Convenção se justifica pelo momento político vivido pelo país naquela década.

\section{A Posição do Brasil como Signatário da Corte Interamericana de Direitos Humanos}

Mesmo após aderir à Convenção Americana em 1992, o Brasil ainda se mostrou resistente quanto à sua aplicação. Como exemplo disso podemos citar a questão - muito discutida - na jurisprudência brasileira do depositário infiel. Isto porque a proibição da prisão por dívidas, contida no artigo 7으, § 70 da citada Convenção, confrontava o ordenamento brasileiro que, com o aval do Supremo Tribunal Federal (STF), permitia essa modalidade de prisão civil. 
Vale destacar que, de acordo com Alberto Silva Santos (2012, p. 106), à época, o Supremo adotava o entendimento de que "a Convenção deveria ser interpretada de acordo com as limitações impostas pelo art. 50, inciso LXVII da Constituição Federal", que elencava a possibilidade de prisão do depositário infiel.

Nesse sentido, Flávia Piovesan (2007, p. 63-64) relembra que o Supremo, no julgamento do HC no 72.131-RJ, em 22 de novembro de 1995, ao tratar dos impactos trazidos pela Convenção Americana de 1969 (Pacto de San José da Costa Rica), entendeu que a Convenção, no que diz respeito ao plano da hierarquia das normas jurídicas, estaria no mesmo nível de eficácia e autoridade das leis ordinárias internas. Dessa maneira, o Congresso Nacional não estaria impedido de aprovar legislação que instituísse a prisão civil do depositário infiel como meio de coerção processual.

O Brasil, na qualidade de Estado-parte da Convenção Interamericana de 1969, somente reconheceu a competência jurisdicional da Corte Interamericana de Direitos Humanos no ano de 1998, por meio do Decreto legislativo no 89, datado de 3 de dezembro, entretanto, conforme recorda Alberto Silva Santos (2012, p.106), a competência restringia-se aos fatos ocorridos a partir do seu reconhecimento, em conformidade com a previsão contida no parágrafo 10 do artigo 62 da Convenção.

Apenas em 2004, com a aprovação da Emenda Constitucional no 45, houve alteração dessa perspectiva. Isso porque a referida emenda, conhecida como "emenda do Judiciário", provocou profundas mudanças no texto constitucional, entre as quais merece destaque a alteração do artigo 5o da Constituição Federal de 1988 (CRFB/1988).

A partir de então o artigo 5ㅇ, § 3ㅇda Constituição Federal de 1988 (CRFB/1988) passou a estabelecer que "os tratados e convenções internacionais sobre direitos humanos que forem aprovados, em cada Casa do Congresso Nacional, em dois turnos, por três quintos dos votos dos respectivos membros, serão equivalentes às emendas constitucionais" (BRASIL, 1988).

Acredita-se que o novo dispositivo do art. 5으, § 3으, vem a reconhecer, de modo explícito, a natureza materialmente constitucional dos tratados de direitos humanos, reforçando, desse modo, a existência de um regime jurídico misto, que distingue os tratados de direitos humanos dos tratados tradicionais de cunho comercial. Isto é, ainda que fossem aprovados pelo elevado quorum de três quintos dos votos dos membros de cada Casa do Congresso Nacional, os tratados comerciais não passariam a ter status formal de norma constitucional tão-somente pelo procedimento de sua aprovação (PIOVESAN, 2007, p. 75).

Ocorre que, mesmo diante da possibilidade de normas internacionais serem recepcionadas no ordenamento brasileiro como emendas constitucionais, ainda vigorava o entendimento do Supremo de que as Convenções e Tratados Internacionais, quando recepcionados, equiparavam-se às leis ordinárias.

Alberto Silva Santos (2012, p. 106) destaca que somente em 2008 o Supremo Tribunal Federal (STF), no julgamento do RE no 466.343-SP, mudou seu posicionamento e passou a reconhecer a impossibilidade da prisão do depositário infiel. A partir de então o STF, além de evidenciar sua nova postura, reconheceu que os tratados internacionais não possuem força constitucional, mas supralegal. 
Vale destacar que, muito embora o Supremo tenha revisto sua posição inicial, a Corte majoritariamente adotou o entendimento de que os tratados internacionais estavam acima da lei nacional, mas abaixo das normas contidas na Constituição Federal de 1988 devido ao seu caráter supralegal. De acordo com Letícia de Oliveira Ribeiro e Gilsilene Passon Picoretti Francischetto (2011, p. 35), entretanto, os direitos humanos, em decorrência de seu caráter universal e de sua indivisibilidade, deveriam prevalecer diante de um conflito com uma norma interna, visto que são mais benéficos à proteção do ser humano.

Para Luciana Genro (2012, p. 71-72) os tratados internacionais que versam sobre os direitos humanos diferem dos demais, uma vez que, por meio deles, os Estados signatários assumem um compromisso perante a comunidade internacional de respeitar essa categoria de direitos sem que, para tanto, seja necessária uma contraprestação, visto que objetivam a proteção dos direitos dos indivíduos que vivem sob a jurisdição dos Estados.

Isso porque a Convenção Americana de Direitos Humanos estabelece, em seus artigos 10 e 2o, deveres aos Estados que a ratificaram. Assim, os Estados-partes comprometem-se a respeitar os direitos e liberdades reconhecidos na Convenção, garantindo seu livre e pleno exercício a qualquer pessoa que esteja sujeita a sua jurisdição, sem que exista nenhum tipo de discriminação. Além disso, os Estados signatários da citada Convenção comprometem-se a adotar, em conformidade com suas normas constitucionais e com as disposições contidas no Tratado, as medidas que forem necessárias para tornar efetivos os direitos e liberdades garantidos por meio da Convenção.

Por essa razão, Luciana Genro (2012, p. 72) destaca que a violação de um Tratado ou norma de Direito Internacional enseja a responsabilização do Estado no que diz respeito à obrigação de reparar os eventuais danos que tenha causado, bem como possibilitou que o ente público sofresse sanções em decorrência da violação causada.

Neste mesmo sentido, Alberto Silva Santos (2012, p. 103) destaca que não serão aceitas manobras de qualquer natureza, sejam legislativas ou judiciais, que contribuam para a limitação dos direitos resguardados pela Convenção. Ademais, destaca que as hipóteses de limitação estão expressamente dispostas na própria Convenção em seu artigo 27, que deve ser lido em conjunto com o artigo 30.

Para esse autor (2012, p. 143), a relativização da soberania estatal que se dá com a adesão à Convenção Americana de Direitos Humanos é um ato de soberania em si mesmo e não pode, portanto, ser compreendido como uma usurpação por parte do Sistema Americano. Isso porque o próprio Estado resolveu voluntariamente aderir à Convenção e também à competência da Corte Interamericana.

É válido destacar que a adesão à Corte deverá ser expressa, na medida em que o artigo 62 da Convenção Interamericana de Direitos Humanos estabelece que o Estado signatário poderá, no momento de ratificação da Convenção ou de adesão a ela, ou em qualquer momento posterior, declarar que reconhece de pleno direito a competência da Corte em quaisquer casos relativos à interpretação ou aplicação do Tratado. É o que ensina Luciana Genro:

As obrigações incorporadas nos Tratados de direitos humanos possuem caráter objetivo, e seu escopo fundamental é a proteção dos direitos do ser humano, e não a dos Estados. Esse é um traço marcante e específico dos Tratados de proteção internacional dos direitos humanos. Ao contrair uma obrigação internacional, isto é, assinar ou ratificar uma 
Pacto ou uma Convenção, o Estado está no exercício pleno da sua soberania e, portanto, não pode invocá-la como razão para justificar o descumprimento desse compromisso (2012, p. 74).

Assim, de acordo com Luciana Genro (2012, p. 73), é possível afirmar que, sob o olhar do Direito Internacional "não importa a visão que predomina no Direito interno a respeito do status dos Tratados Internacionais de direitos humanos". Isso porque as violações dos direitos humanos sempre ensejarão a reponsabilidade internacional, mesmo que a violação seja amparada pela Constituição do país transgressor da Convenção.

\section{Caso Damião Ximenes Lopes}

Entre os casos em que o Brasil figurou como réu perante a Corte Interamericana de Direitos Humanos merece destaque o caso de Damião Ximenes Lopes, usuário do Sistema Único de Saúde (SUS), acometido de adoecimento mental que, internado em 10 de outubro de 1999 na denominada Casa de Repouso de Guararapes, instituição de caráter privado que operava no âmbito do Sistema Único de Saúde (SUS) no município de Sobral, no Ceará, faleceu após apenas 3 (três) dias de internação, no dia 4 de outubro de 1999. Neste sentido, Letícia de Oliveira Ribeiro e Gilsilene Passon Picoretti Francischetto destacam que:

É de domínio público que os portadores de deficiência mental se encontram em situação de vulnerabilidade, razão pela qual merecem especial atenção e proteção do Estado. Não obstante tal constatação seja de sapiência pública, o Estado Brasileiro não se atentou para as cautelas devidas, respondendo por isso perante a Corte Interamericana de Direitos Humanos (2011, p. 29).

Após a morte da vítima, o hospital psiquiátrico apresentou laudo em que apontava a causa de sua morte como indeterminada. A família de Damião Ximenes Lopes, no entanto, em decorrência da inércia e morosidade da Justiça, bem como das condições desumanas e indignas a que foi submetida a vítima durante sua internação, apresentou o caso para análise da Comissão Interamericana de Direitos Humanos.

Assim, como bem ensinam Letícia de Oliveira Ribeiro e Gilsilene Passon Picoretti Francischetto (2011, p. 34), com a exclusão e a invisibilidade das pessoas acometidas por adoecimento mental, o Princípio da Igualdade, formalmente assegurado na Constituição de 1988 e na Declaração dos Direitos do Homem de 1948, é desrespeitado, culminando, de igual maneira, com a inobservância dos direitos humanos. As autoras destacam, ainda, que:

[...] Em razão das características da universalidade e da indivisibilidade, conclui-se pela legitimidade da interferência internacional no ordenamento jurídico pátrio, no caso Damião Ximenes Lopes, para transcender do plano formal para o efetivo, a concretização da proteção aos Direitos Humanos, que o Estado Brasileiro foi incapaz de garantir (2011, p. 34-35).

Dessa forma, a Comissão Interamericana de Direitos Humanos apresentou a demanda à Corte Interamericana em desfavor do Brasil, o que originou a denúncia no 12.237, recebida na Secretaria da Comissão em 22 de novembro de 1999. Vale destacar que a Comissão pretendia 
que a Corte decidisse se o Estado brasileiro deveria responder pela inobservância de vários direitos previstos na Convenção Americana de 1969, entre os quais ganham destaque o direito à vida, direito à integridade judicial, direito às garantias judicias e o direito à proteção judicial.

Para que se compreenda a relevância do princípio da igualdade e a proteção aos direitos humanos, aos portadores de deficiência mental, indispensável se mostra a análise de seus precedentes históricos, para que posteriormente se compreenda a relevância da interferência da Corte Interamericana no caso de Damião Ximenes Lopes (RIBEIRO; FRANCISCHETTO, 2011, p. 34).

Assim, a Corte Interamericana de Direitos Humanos condenou, pela primeira vez, no ano de 2006, o Brasil em uma sentença de mérito em decorrência das diversas violações aos direitos humanos inerentes às pessoas com adoecimento mental evidenciadas no caso em tela. É válido relembrar que, naquela época, o Brasil havia recepcionado a Convenção Interamericana de Direitos Humanos como simples lei ordinária.

Nesse contexto, parece salutar trazer a reflexão de que, muito embora as pessoas com adoecimento mental sejam materialmente vistas pelos integrantes da sociedade, são ignoradas e, em razão disso, passam a integrar um grupo socialmente excluído. Ademais, para além do estigma que é atribuído a esses indivíduos, a falta de reconhecimento destas pessoas como sujeito de direitos funciona como óbice que impede sua humanização.

Não é incomum que as pessoas que padeçam de algum tipo de sofrimento mental sejam rebaixadas, na maioria das vezes, a condições verdadeiramente animalescas. Dormem, comem e são tratadas como animais, motivo pelo qual esquecem "o que é ser gente". Além disso, dissemina-se a crença de que esse grupo oferece risco às demais pessoas, razão pela qual deveriam ser mantidas trancafiadas.

Logo, não é preciso empreender muitos esforços para constatar que as pessoas com adoecimento mental não são tratadas como pessoas - são desumanizadas - e, portanto, deixam de existir para a sociedade que, por sua vez, via de regra, ignora por completo suas necessidades. ${ }^{1}$ Nesse contexto, faz sentido destacar os ensinamentos de Boaventura de Sousa Santos, de que a "produção de não existência ocorrerá sempre que uma dada entidade é desqualificada e tornada invisível, ininteligível ou descartável de um modo irreversível (2006, p. 102)".

Boaventura de Sousa Santos (2006, p. 102-103) trabalha com cinco modos de produção da não existência, e, entre elas, é possível destacar a "lógica da classificação social". Esse modo de produção da não existência consiste, basicamente, na distribuição de categorias que naturalizam hierarquias.

Para Boaventura de Sousa Santos (2006, p. 102) a relação de dominação é a consequência e não a causa dessa hierarquia e pode ser considerada como obrigação daquele que é classificado como superior. Nesse viés, o autor ensina que "quem é inferior, porque é insuperavelmente inferior, não pode ser uma alternativa credível a quem é superior" (2006, p. 103). 
O autor propõe, por meio de uma sociologia das ausências - investigação que visa a demonstrar que o que não existe é, na verdade, ativamente produzido como não existente cinco ecologias que substituem as monoculturas para superar os modos de produção de não existência.

É possível verificar que a sociedade elege as diferenças que são capazes de inferiorizar o indivíduo de sua condição humana. As pessoas com adoecimento mental são socialmente inferiorizadas, entretanto precisam ser reconhecidas como seres humanos dotados de direitos e garantias, assim como os demais. Para tanto, Boaventura de Sousa Santos trata de uma ecologia dos reconhecimentos que versa sobre a "lógica da produção de ausências e a lógica da classificação social" (2006, p. 110).

O sociólogo (2006, p. 110) argumenta, ainda, que o poder capitalista ocidental e moderno arrogou para si o privilégio de decidir quem é igual e quem é diferente. Assim, por meio de uma sociologia das ausências, Boaventura de Sousa Santos (2006, p. 102-110) propõe uma desconstrução da diferença e da hierarquia. O autor ensina que "as diferenças que subsistem quando desaparece a hierarquia torna-se uma denúncia poderosa das diferenças que a hierarquia exige para não desaparecer" (2006, p. 110-111).

Em síntese, Boaventura de Sousa Santos defende que o reconhecimento torna-se necessário à medida que há um aumento da diversidade cultural e social dos sujeitos coletivos que lutam por sua emancipação social, bem como na medida em que há um aumento da variedade das formas de dominação e de opressão contra as quais combatem e a multiplicidade de escalas das lutas em que se envolvem.

Posto isso, é certo que além do reconhecimento social, é necessário, para garantir a visibilidade das pessoas com adoecimento mental, que sejam criados e instituídos instrumentos capazes de promover a proteção desses indivíduos socialmente fragilizados. Logo, é indispensável que sejam criadas leis, institutos, estruturas de apoio e outras ferramentas capazes de garantir a proteção das minorias sociais. Nesse sentido, Boaventura de Sousa Santos entende que:

Nas suas lutas, o "cultural" incorpora e modela racionalidades alternativas sem constituir uma esfera diferenciada da vida social, como sucede na concepção liberal de cultura. 0 reconhecimento da diferença cultural, da identidade colectiva, da autonomia ou autodeterminação deu origem a novas formas de luta (por acesso igualitário aos direitos coletivos; pela defesa e promoção de quadros normativos alternativos ou tradicionais, de formas comunitárias de meios de produção, de meios de subsistência ou de resolução de conflitos, etc.). Assim, a idéia de uma cidadania multicultural, individual ou colectiva adquire um significado mais preciso como palco privilegiado de lutas pela articulação entre a exigência do reconhecimento cultural e político e a redistribuição econômica e social (2006, p. 111).

É necessário pontuar que, em uma sociedade como a brasileira, profundamente marcada pelo preconceito, discriminação e exclusão social, faz-se necessária a edição de leis que sejam eficazes no sentido de coibir práticas desumanizadoras, promovendo, dessa forma, a proteção da dignidade e a inclusão das pessoas portadoras de doença mental. 
Vale destacar que Boaventura de Sousa Santos (2006, p. 111-112) entende que a ecologia dos reconhecimentos alarga o círculo das reciprocidades, também chamado de diferenças iguais - e cria formas de inteligibilidade recíproca. Assim, a multidimensionalidade das formas de dominação e de opressão contribui para o surgimento de formas de luta e de resistência que mobilizam diferentes atores sociais, vocabulários e recursos inteligíveis entre si.Ao analisar a sentença condenatória proferida em desfavor do Brasil pela Corte Interamericana de Direitos Humanos no caso Damião Ximenes Lopes, é possível constatar que existem consequências advindas da condenação internacional do Estado brasileiro, tais como a condenação pecuniária, a criação de leis, a elaboração de estrutura de apoio para pessoas portadoras de deficiência mental, a capacitação dos profissionais da área da saúde mental, entre outros, conforme se verificará no tópico a seguir.

\section{As Consequências Advindas da Condenação do Brasil na Corte Interamericana de Direitos Humanos no Caso Damião Ximenes Lopes}

De acordo com Cristiano Paixão et al (2007, p. 24), a condenação do Estado brasileiro pela Corte Interamericana de Direitos Humanos no caso Brasil versus Damião Ximenes, não representou apenas um exemplo de atuação para garantir a proteção dos direitos humanos, mas funcionou, na verdade, como uma decisão que deu destaque e também lançou novas bases para o direito das pessoas acometidas de sofrimento mental.

A sentença proferida pela Corte, conclui André de Carvalho Ramos (2006), reconheceu a responsabilidade do Estado brasileiro em decorrência da prática de ato de particular que prestava serviços sob a supervisão e fiscalização do ente público. Em outras palavras, a despeito de a Casa de Repouso de Guararapes ser uma instituição privada, a Corte admitiu a responsabilização do Estado do Ceará em razão dos atos praticados pelos funcionários da clínica, uma vez que a instituição estava sendo financiada e supervisionada pelas verbas públicas do Sistema Único de Saúde (SUS).

Considerando que toda pessoa que se encontre em situação de vulnerabilidade é titular de uma proteção especial, a Corte entendeu ser necessário o cumprimento de deveres especiais por parte do Estado de forma a atender às obrigações gerais de respeito e garantia dos direitos humanos. Dentre os deveres do Estado com relação às pessoas portadoras de deficiência mental, a Corte ressaltou o dever de cuidar. Este dever, bem como o de prevenir a vulneração da vida e da integridade pessoal não foram cumpridos pelo Estado brasileiro no caso em comento, gerando a responsabilidade internacional do Estado (PAIXÃO, 2007, p. 15).

Conforme demonstrado anteriormente e, de acordo com Cristiano Paixão (2007, p. 20), a Corte Interamericana de Direitos Humanos, ao condenar o Estado brasileiro a cumprir com sua obrigação de garantir, a cada cidadão, uma prestação jurisdicional efetiva e a instituir políticas públicas na área da saúde mental, obrigou o Estado brasileiro a mudar a forma como tratava e convivia com as pessoas acometidas de sofrimento psíquico. Assim, a sentença da Corte, de acordo com o autor, deu início a um novo momento para os significados e para força dos direitos humanos. 
Posto isso, considerando que o Estado do Ceará delegou a prestação de um serviço público para uma entidade privada, é dever do ente público garantir e zelar pela qualidade do serviço prestado, bem como realizar contínuas fiscalizações, de forma que possam ser identificadas quaisquer tipos de irregularidades. Ocorre que, no caso em estudo, podemos verificar que o ente público simplesmente deixou de fiscalizar os serviços prestados pela Casa de Repouso de Guararapes, o que contribuiu diretamente para a morte do paciente Damião Ximenes Lopes.

Este também foi o entendimento da Corte Internacional de Direitos Humanos, de acordo com Cristiano Paixão:

A Corte considerou que os Estados têm o dever de regulamentar e fiscalizar toda a assistência de saúde prestada às pessoas sob sua jurisdição, como dever especial de proteção à vida e à integridade pessoal, independentemente de ser a entidade que presta esses serviços de caráter público ou privado. A regulamentação e fiscalização das entidades privadas que prestam serviços públicos devem ocorrer de forma permanente. [...] (2007, p. 13).

Cristiano Paixão (2007, p. 13) destaca, ainda, que na sentença a Corte manifestou-se expressamente quanto ao direito à vida, à integridade e ao respeito à autonomia das pessoas com adoecimento mental em relação ao tratamento de saúde a ser adotado que, por sua vez, não pode ser encarado de maneira absoluta, posto que, em algumas situações, a necessidade do paciente pode exigir que algumas medidas sejam realizadas sem o seu consentimento. Também relembra que, no caso em tela, a Corte entendeu que o Estado tem responsabilidade internacional em decorrência do descumprimento de seu dever de regulamentar e fiscalizar o atendimento médico de saúde.

De fato, não é preciso muito esforço para constatar que a condenação do Brasil pela Corte Interamericana de Direitos Humanos em decorrência da morte de Damião Ximenes Lopes representou uma verdadeira mudança de perspectiva no que diz respeito ao tratamento atribuído às pessoas acometidas por adoecimento mental.

Isso porque um dos pontos resolutivos decididos por unanimidade da Corte na sentença proferida no caso Brasil versus Damião Ximenes Lopes, estipulou que o Brasil deveria continuar a desenvolver programas de formação e capacitação para os profissionais psiquiatras e psicólogos, enfermeiros e auxiliares de enfermagem, bem como para os demais profissionais responsáveis por realizar atendimentos na área de saúde mental.

André de Carvalho Ramos (2006) entende que a sentença proferida no ano de 2006 pela Corte Interamericana de Direitos Humanos expõe as mazelas do Brasil, ou seja, demonstra que à época da morte de Damião Ximenes Lopes, paciente da Clínica de Repouso de Guararapes (CE), não se atribuía a devida atenção e tratamento às pessoas com adoecimento psíquico que se encontravam internadas nas instituições - públicas ou privadas - que ofereciam esse tipo de serviço de prestação à saúde.

Ficou provado neste caso que no momento dos fatos não se dispensava adequada atenção ao tratamento e internação de pessoas portadoras de deficiência mental, como no caso da Casa de Repouso Guararapes, instituição que oferecia esse serviço no Sistema Único de Saúde. Embora se destaque o fato de que o Estado adotou diversas medidas destinadas a melhorar esse atendimento, este Tribunal considera que o Estado deve continuar a desenvolver um programa de formação e capacitação para o pessoal médico, 
de psiquiatria e psicologia, de enfermagem e auxiliares de enfermagem, bem como para todas as pessoas vinculadas ao atendimento de saúde mental, em especial sobre os princípios que devem reger o tratamento a ser oferecido às pessoas portadoras de deficiência mental, de acordo com as normas internacionais sobre a matéria e as dispostas nesta Sentença (CORTE..., 2006).

Nesse contexto, merece destaque a Lei no 10.216/2001, que versa "sobre a proteção e os direitos das pessoas portadoras de transtornos mentais e redireciona o modelo assistencial em saúde mental" (BRASIL, 2001) já existente ao tempo da promulgação da sentença da Corte Interamericana de Direitos Humanos no caso Brasil versus Damião Ximenes Lopes.

Ensina Cristiano Paixão (2007, p. 23) que a Lei no 10.216/2001 é resultado da luta pelos direitos das pessoas com adoecimento psíquico e é verdadeiramente responsável por redirecionar o modelo de assistência em saúde mental no Brasil, sendo um exemplo do potencial emancipatório dos direitos humanos. Assim, de acordo com o autor, a norma foi elaborada para garantir que as pessoas com adoecimento mental fossem tratadas com igualdade, visto que promoveu a inclusão desses indivíduos no âmbito da cidadania.

Logo, é possível constatar que há uma quebra de paradigma quanto à percepção das pessoas com adoecimento mental na sociedade em geral, visto que, mediante a promulgação da citada Lei, passam a ser encaradas como sujeitos de direitos que merecem proteção estatal não apenas em decorrência da situação de vulnerabilidade em que se encontram, mas, principalmente, por serem vistas como cidadãos que integram a sociedade.

Merece destaque o artigo 2o, parágrafo único, da Lei 10.216/2001, ${ }^{2}$ que institui um rol de direitos inerentes às pessoas acometidas por adoecimento mental e, em virtude disso, representa um grande avanço para o movimento antimanicomial, dado que, pela primeira vez, se estabelece como um dos direitos inerentes às pessoas que padecem de transtornos mentais a possibilidade de serem tratadas, preferencialmente, em serviços comunitários de saúde mental.

Cabe observar que, muito embora a referida Lei tenha sido promulgada em 2001, ou seja, antes da publicação da sentença da Corte Interamericana de Direitos Humanos no ano de 2006, representou um grande avanço para a proteção dos direitos das pessoas com adoecimento mental, posto que, conforme é possível aduzir pelo artigo 6o da Lei № 10.216/01

\footnotetext{
Artigo 2 ㅇ...] I - ter acesso ao melhor tratamento do sistema de saúde, consentâneo às suas necessidades;

II - ser tratada com humanidade e respeito e no interesse exclusivo de beneficiar sua saúde, visando alcançar sua recuperação pela inserção na família, no trabalho e na comunidade;

III - ser protegida contra qualquer forma de abuso e exploração;

IV - ter garantia de sigilo nas informações prestadas;

V - ter direito à presença médica, em qualquer tempo, para esclarecer a necessidade ou não de sua hospitalização involuntária;

VI - ter livre acesso aos meios de comunicação disponíveis;

VII - receber o maior número de informações a respeito de sua doença e de seu tratamento;

VIII - ser tratada em ambiente terapêutico pelos meios menos invasivos possíveis;

IX - ser tratada, preferencialmente, em serviços comunitários de saúde mental.
} 
(BRASIL, 2001), a internação psiquiátrica passou a ser realizada somente mediante laudo médico circunstanciado que fosse capaz de demonstrar os motivos para a hospitalização do paciente.

Nesse contexto, sob o apoio da Lei no 10.216/2001, a hospitalização, também conhecida como internação psiquiátrica, passou a ser encarada como exceção para promoção do tratamento do paciente com adoecimento mental. Desta maneira, é possível observar que a legislação, mesmo que com certa timidez, inovou ao propor que as pessoas com adoecimento psíquico recebam tratamento fora dos hospitais psiquiátricos, o que contribui para o processo de reinserção desses indivíduos na sociedade. Nesse sentido, é correto afirmar que essa mudança de postura constitui um dos pilares da reforma psiquiátrica.

Mesmo com a Lei no 10.216/2011, entretanto, a Corte Interamericana de Direitos Humanos definiu na sentença do caso Damião Ximenes que o Brasil deveria continuar empregando esforços no sentido de ampliar a proteção e garantir os direitos inerentes às pessoas com adoecimento psíquico.

Assim, a Corte Interamericana de Direitos Humanos, ao elaborar a sentença do caso em análise, estabeleceu deveres para o Estado em relação às partes lesadas, bem como decretou que o ente público pagasse, em dinheiro, compensação para os familiares de Damião Ximenes Lopes, com o montante sendo fixado a título de dano material e imaterial no prazo de 1 (um) ano. Por sua vez, para garantir a não repetição de situações similares, a Corte determinou que o Estado brasileiro continuasse a promover programas de capacitação e formação para os profissionais que atuam na área de saúde mental.

Cristiano Paixão ressalta que:

Em atenção às formas de reparação solicitadas, a Corte estabeleceu como deveres do Estado em relação às partes lesadas: [...] Quanto à compensação, foi estabelecido o dever de pagar em dinheiro para Albertina Viana Lopes e Irene Ximenes Lopes Miranda, no prazo de um ano, o montante fixado a título de indenização por dano material e imaterial, pagar em dinheiro, no prazo de um ano, o montante fixado a título de custas e gastos gerados no âmbito interno e no processo internacional perante o sistema interamericano de proteção dos direitos humanos para Albertina Viana Lopes. Em relação à garantia de não repetição, foi estabelecido o dever de o Estado brasileiro continuar a desenvolver um programa de formação e capacitação para o pessoal médico, de psiquiatria e psicologia, de enfermagem e auxiliares de enfermagem e para todas as pessoas vinculadas ao atendimento de saúde mental. $(2007$, p. 18$)$.

O fato é que a sentença proferida pela Corte Interamericana de Direitos Humanos fez com que o município de Sobral, local de funcionamento da Casa de Repouso de Guararapes, criasse uma Rede de Atenção à Saúde Mental (Raism). Além disso, em âmbito nacional, a condenação do Brasil influenciou diretamente a instituição de Centros de Atenção Psicossociais (Caps), criação de residências terapêuticas e de unidades de internação psiquiátricas em hospitais, bem como instalação de ambulatórios de Psiquiatria regionalizados e Estratégia em Saúde da Família (ESF). 
Em resumo, de acordo com Cristiano Paixão (2007, p. 23), a análise do caso Damião Ximenes Lopes demonstra como a condenação do Brasil pela Corte Interamericana de Direitos Humanos também representou uma censura em relação à política pública de saúde mental que, muito embora fosse avançada em seus princípios, era deficitária no que diz respeito a sua aplicação.

O autor (2007, p. 24), portanto, defende que a promulgação da Lei n 10.216/2001 e a pressão exercida pela sentença proferida pela Corte Interamericana de Direitos Humanos no caso Brasil versus Damião Ximenes Lopes contribuíram, de maneira decisiva, para a extinção dos hospitais psiquiátricos, chamados manicômios, e sua substituição por centros de atenção e cuidado, nos quais o tratamento é desenvolvido e pautado na liberdade dos indivíduos com adoecimento mental. Assim, em razão da proteção, cuidado e respeito em relação a essas pessoas instituídos pela Corte Internacional de Direitos Humanos os métodos cruéis, até então aplicados como forma de tratamento para os transtornos psíquicos, passaram a, progressivamente, ceder lugar para os tratamentos que zelam pela condição humana dos indivíduos.

Dessa maneira, é preciso empreender esforços e trabalhar para que a sociedade volte a enxergar essas pessoas como verdadeiros seres humanos em situação de extrema vulnerabilidade, carecedores de atenção e assistência em virtude de sua condição. Para tanto é preciso, mais do que nunca, garantir às pessoas com deficiência mental proteção integral no que diz respeito aos seus direitos civis, políticos e, principalmente, no que se relaciona aos seus direitos e garantias fundamentais.

\section{Considerações Finais}

Durante o desenvolvimento do presente artigo buscou-se demonstrar que a condenação do Estado brasileiro no caso Damião Ximenes Lopes versus Brasil impactou diretamente o tratamento recebido pelas pessoas acometidas por adoecimento mental.

Para tanto, realizou-se uma sucinta análise sobre o Sistema Interamericano de Direitos Humanos, dando ênfase à Convenção Americana de 1969, denominada de Pacto de San José da Costa Rica, responsável pela criação da Corte Interamericana de Direitos Humanos.

Foi possível verificar que, em virtude do posicionamento adotado pelo Supremo Tribunal Federal (STF) à época da adesão à Convenção pelo Estado brasileiro, o Tratado Internacional equiparava-se à Lei Ordinária no que diz respeito a sua hierarquia e eficácia. Além disso, verificou-se que o Brasil somente reconheceu a competência da Corte Interamericana de Direitos Humanos no ano de 1998.

A mudança desse panorama ocorreu somente em 2004, quando a Emenda Constitucional no 45/2004 passou a estabelecer que os Tratados Internacionais que versam sobre direitos humanos, quando aprovados em cada Casa do Congresso Nacional, em dois turnos, por três quintos dos votos, serão equivalentes às emendas constitucionais.

Ocorre que, nessa época ainda vigorava o entendimento do Supremo de que as Convenções e Tratados Internacionais se equiparavam às leis ordinárias. Assim, somente em 2008, no julgamento do RE $\mathrm{n} 0466.343 / \mathrm{SP}$, a Corte reviu seu entendimento, passando a reconhecer que os tratados - de cunho internacional - possuem força supralegal, ou seja, estão acima das leis brasileiras e abaixo da Constituição Federal de 1988. 
Assim, em razão da mudança da postura até então adotada pelo Supremo Tribunal Federal, houve uma troca de percepção do Estado brasileiro quanto aos efeitos que eventualmente poderiam surgir em razão de uma condenação internacional.

Nesse sentido, o artigo traz o caso emblemático de Damião Ximenes Lopes, pessoa com adoecimento mental que veio a óbito após 3 (três) dias de internação na Casa de Repouso de Guararapes (CE). A família da vítima, inconformada com o laudo apresentado pela instituição, em que a morte constava como indeterminada e com a inércia e morosidade do Judiciário brasileiro, resolveu buscar ajuda na Comissão Internacional de Direitos Humanos que, por sua vez, submeteu a denúncia à Corte Interamericana de Direitos Humanos.

Assim, em 2006, o Brasil foi condenado pela Corte Interamericana de Direitos Humanos no caso Damião Ximenes Lopes, em virtude da violação de diversos direitos inerentes às pessoas acometidas por adoecimento psíquico. É válido destacar que a Corte reconheceu a ineficácia da legislação brasileira em promover a proteção dos direitos das pessoas com adoecimento mental.

Isso porque, muito embora à época da publicação da sentença já vigorasse a Lei no $10.216 / 2001$, que trata da proteção e dos direitos das pessoas portadoras de transtornos mentais e redireciona o modelo assistencial em saúde mental, a Corte entendeu ser necessário que o Brasil continuasse a empregar esforços no sentido de desenvolver programas de formação e capacitação para os profissionais psiquiatras e psicólogos, enfermeiros e auxiliares de enfermagem, bem como para todo e qualquer profissional responsável por realizar atendimentos na área de saúde mental.

Logo, percebe-se que a condenação do Brasil pela Corte Interamericana de Direitos Humanos, além de determinar a instituição e a exigência de constante melhora e atenção em relação às políticas públicas em saúde mental, contribuiu para dar visibilidade às pessoas acometidas por adoecimento psíquico. Isso porque a condenação não só obrigou o Estado brasileiro a dispensar maior atenção a esses indivíduos - por meio da adoção de tratamentos compatíveis com o princípio da dignidade humana ou políticas de saúde - mas funcionou como meio de reconhecimento de que essas pessoas são sujeitos de direitos e, como tal, merecem ser protegidas pelo Estado brasileiro.

\section{Referências}

BRASIL. Constituição [da] República Federativa do Brasil de 1988. 1988. Disponível em: <http://www.planalto. gov.br/ccivil_03/constituicao/ConstituicaoCompilado.htm>. Acesso em: 28 jun. 2017.

BRASIL. Lei no 10.216/2001 de 6 de abril de 2001. Dispõe sobre a proteção e os direitos das pessoas portadoras de transtornos mentais e redireciona o modelo assistencial em saúde mental. Disponível em: <http://www.planalto.gov.br/ccivil_03/leis/leis_2001/l10216.htm>. Acesso em: 28 jun. 2017.

CORTE INTERAMERICANA DE DIREITOS HUMANOS. Sentença Caso Ximenes Lopes versus Brasil. Julgado em: 4 jul. 2006. Disponível em: <http://webcache.googleusercontent.com/search?q=cache:s10hOLvxG1AJ:direitosp. fgv.br/sites/direitosp.fgv.br/files/narrativa_final_-_ximenes.pdf+\&cd=5\&hl=pt-BR\&ct=clnk\&gl=br>. Acesso em: 28 jun. 2017.

COSTA RICA. Convenção Americana de Direitos Humanos. 1969. Disponível em: <http://www.cidh.oas.org/basicos/portugues/c.Convencao_Americana.htm>. Acesso em: 28 jun. 2017.

GENRO, Luciana. Direitos humanos: o Brasil no banco dos réus. São Paulo: LTr, 2012.

PAIXÃO, Cristiano. Caso Ximenes Lopes versus Brasil - Corte Interamericana de Direitos Humanos: Relato e Reconstrução Jurisprudencial. 2007. Disponível em: <http://direitosp.fgv.br/sites/direitosp.fgv.br/files/narrativa_final_-_ximenes.pdf>. Acesso em: 28 jun. 2017. 
PELLEGRINI, Marcelo. Em extinção, manicômios podem voltar disfarçados. In: Carta Capital. 2016. Disponível em: $\quad$ <https://www.cartacapital.com.br/sociedade/em-extincao-manicomios-podem-voltar-disfarcados-7374. html>. Acesso em: 28 jun. 2017.

PIOVESAN, Flávia. Direitos humanos e o Direito constitucional internacional. 8. ed. São Paulo: Saraiva, 2007.

RIBEIRO, Letícia de Oliveira; FRANCISCHETTO, Gilsilene Passon Picoretti. O reflexo da ausência de direitos humanos: o caso internacional de Damião Ximenes Lopes. In: BUSSINGUER, Elda Coelho de Azevedo (Org.). Direitos fundamentais: pesquisas. Curitiba: CRV, 2011. p. 31-36. V. 1.

RAMOS, André Carvalho de. Reflexões sobres as vitórias do caso Damião Ximenes. In: Consultor Jurídico, 2006. Disponível em: <http://www.conjur.com.br/2006-set-08/reflexoes_vitorias_damiao_ximenes>. Acesso em: 28 jun. 2017.

SANTOS, Alberto Silva. A internacionalização dos Direitos Humanos e o Sistema Interamericano de Proteção. Belo Horizonte: Arraes, 2012.

SANTOS, Boaventura de Sousa. Para uma concepção multicultural de direitos humanos. 1997. Disponível em: <http://www.boaventuradesousasantos.pt/media/pdfs/Concepcao_multicultural_direitos_humanos_RCCS48. PDF>. Acesso em: 28 jun. 2017.

. A gramática do tempo: para uma nova cultura política. São Paulo: Cortez, 2006.

SUPREMO TRIBUNAL FEDERAL. Recurso Especial no 466.343/ SP. Rel. Ministro Cezar Peluso. Tribunal Pleno. Julgado em 3 dez. 2008. Publicado em 4 jun. 2009. Disponível em: <http://jurisprudencia.s3.amazonaws. com/STF/IT/RE_466343_SP_1278971570481.pdf?Signature=rtrHFfeGT\%2BHEh\%2FhWyltN6DHsPDQ\%3D\&Expires=1480674973\&AWSAccessKeyId=AKIAIPM2XEMZACAXCMBA\&response-content-type=application/pdf\&x-amz-meta-md5-hash=49d88a9d9571e722a5d5e3a66747d4fd>. Acesso em: 28 jun. 2017.

. Habeas Corpus no 72.131/ RJ. Rel. Ministro Marco Aurélio Tribunal Pleno. Julgado em 23 nov. 1995. Publicado em ago. 2003. Disponível em: <http://stf.jusbrasil.com.br/jurisprudencia/2884009/habeas-corpus-hc-72131-rj>. Acesso em: 28 jun. 2017. 